\title{
A Comparative Evaluation of Remineralizing Potential of Three Commercially Available Remineralizing Agents: An In Vitro Study
}

\author{
Darshana Vinod ${ }^{1}$, Anjana Gopalakrishnan ${ }^{2}$, Saravanakumar M Subramani $^{3}$, Muralikrishnan Balachandran $^{4}$, \\ Vidya Manoharan ${ }^{5}$, Amrutha Joy ${ }^{6}$
}

\begin{abstract}
Aim: An in vitro study to evaluate and compare the remineralization potential of commercially available remineralizing agents containing silver diamine fluoride (SDF), casein sucrose phosphate (CSP), casein phospho peptide-amorphous calcium phosphate (CPP-ACP) using DIAGNOdent. Materials and methods: Thirty freshly extracted premolars for orthodontic treatment were collected. Specimens were randomly divided into 3 groups of 10 each: group I: SDF, group II: CSP, group III: CPP-ACP. The samples were subjected to DIAGNOdent analysis for recording the baseline values. Specimens were placed in demineralizing solution incubated at $37^{\circ} \mathrm{C}$ for 72 hours. DIAGNOdent values were recorded after demineralization. Following this, remineralization procedure was carried out using 3 different remineralizing agents: group I samples with SDF, group II with CSP, and group III with CPP-ACP. The remineralization procedure was performed to group I once and repeated for 14 days for group II and group III and storage solution was changed every 24 hours. The samples were subjected to DIAGNOdent analysis after 72 hours, 7 days, and 14 days and values were recorded.

Results: The data were analysed using Statistical Package for the Social Sciences (SPSS) with analysis of variance (ANOVA) and post hoc test. Intragroup comparison of DIAGNOdent readings showed a highly significant difference between baseline, postdemineralization, and postremineralization values. Among intergroup comparison, SDF showed maximum remineralization values followed by CSP and CPP-ACP, respectively.

Conclusion: Silver diamine fluoride, CSP, and CPP -ACP are proven to possess remineralization potential.

Clinical significance: A comparative evaluation of these three remineralizing agents will aid in identifying most potent and effective agent in treating initial caries lesions in an effective noninvasive and child-friendly manner.

Keywords: Casein phospho peptide-amorphous calcium phosphate, Casein sucrose phosphate, DIAGNOdent, Laboratory research, Silver diamine fluoride.

International Journal of Clinical Pediatric Dentistry (2020): 10.5005/jp-journals-10005-1715
\end{abstract}

\section{INTRODUCTION}

The current trend in caries management is early detection and targeted noninvasive management of invasive reversible lesions using novel remineralization agents. ${ }^{1}$ Chemical demineralization of teeth is caused by acidic attack through two primary means: dietary acid consumed through food or drink/drugs and microbial attack from bacteria present in the mouth. ${ }^{2-4}$ During an acidic attack, or a typical demineralization regime, chemical dissolution of both the organic and inorganic matrix components takes place. This is brought about by the water content of enamel and dentine, which facilitate acid diffusion in and mineral content out of tooth. ${ }^{5}$ Initial demineralization is a reversible process; hence, the partially demineralized hydroxyapatite (HA) crystals in teeth can grow to their original size if they are exposed to oral environments that favor remineralization. ${ }^{6}$ Dental caries can be arrested or repaired by enhancing teeth mineralization at early stages. ${ }^{7}$

The high concentration of calcium and phosphate in saliva is the major mineral source in the oral environment. The contribution of calcium, phosphate, and hydroxyl ions present in saliva to apatite deposition is fundamental. Remineralization starts when the salivary $\mathrm{pH}$ increases beyond the critical $\mathrm{pH}$ level. This bounds the calcium and phosphate into the enamel with the help of saliva, fluorides, or other agents resulting in the
1-3,5,6 Department of Pediatric and Preventive Dentistry, Royal Dental College, Palakkad, Kerala, India

${ }^{4}$ Department of Pediatric and Preventive Dentistry, St. Gregorios Dental College, Chelad, Kerala, India

Corresponding Author: Darshana Vinod, Department of Pediatric Dentistry, Royal Dental College, Palakkad, Kerala, India, Phone: +91 9946216630, e-mail: dr.v.darshana@gmail.com

How to cite this article: Vinod D, Gopalakrishnan A, Subramani SM, et al. A Comparative Evaluation of Remineralizing Potential of Three Commercially Available Remineralizing Agents: An In Vitro Study. Int J Clin Pediatr Dent 2020;13(1):61-65.

Source of support: Nil

Conflict of interest: None

formation of rebuilt crystalline structures of fluoridated $\mathrm{HA}$ and fluorapatite. ${ }^{7}$

Role of fluoride in remineralization is long known and timetested to be the effective method of remineralization. ${ }^{7}$ With the advancement in science and research, newer fluoride containing agents and nonfluoride containing agents has been introduced in the market as remineralizing agents such as SDF, CPP-ACP, and CSP. In order to guide researchers and clinicians in the appropriate selection and application of the different technologies, new materials require validation and comparison with established 
methods. Therefore, this current study compares the effectiveness of the three newer remineralizing agents SDF, CSP, and CPP-ACP.

\section{Materials and Methods}

This study was done in the Department of Pedodontics and Preventive dentistry, in collaboration with the Department of Biochemistry.

Test agents used were SDF, FAGAMIN ${ }^{\oplus}$; CSP, TOOTHMIN ${ }^{\top M}$; and CPP-ACP, GC Tooth Mousse ${ }^{\circledR}$.

Sample collection: freshly extracted premolars for orthodontic reasons were collected.

Teeth with no evidence of caries on visual inspection, no evidence of white spot lesion, no enamel cracks and showed a DIAGNOdent score: 0-7 were included, whereas teeth that had restorations or developmental defects and DIAGNOdent score more than 7 were excluded.

\section{Sample Preparation}

Thirty teeth that followed the inclusion criteria were selected. The teeth were thoroughly cleansed with ultrasonic scaler and polished with pumice slurry using polishing brush and rubber cup. The samples were air-dried and $3 \times 3 \mathrm{~mm}$ label placed at the center of buccal surface of the crown of teeth to limit the area of study. Remaining portion of tooth was painted with nail varnish and kept to dry. The samples were randomly grouped into 3 of 10 each: group I: SDF, group II: CSP, group III: CPP-ACP. Later, the labels were removed and baseline values were recorded using DIAGNOdent.

\section{Demineralization}

Each sample was kept in freshly prepared $15 \mathrm{~mL}$ demineralizing solution ( $\mathrm{pH}-4.5)$ containing the following:

$\mathrm{CaCl}_{2}: 2.2 \mathrm{mM}$

$\mathrm{NaH}_{2} \mathrm{PO}_{4}: 2.2 \mathrm{mM}$

Acetic acid: $0.05 \mathrm{M}$

$\mathrm{NaOH}: 50 \%$.

Demineralization was done for 72 hours at $37^{\circ} \mathrm{C}$ in incubator. After which postdemineralization values were recorded using DIAGNOdent. The samples were thoroughly rinsed with deionized water and kept for wash out period of 24 hours.

\section{Remineralization}

During this period, the samples were kept in artificial saliva $(\mathrm{pH}-$ 7.2), which was freshly prepared. This artificial saliva was changed every 24 hours to maintain ionic balance and $\mathrm{pH}$ of solution.

Storage solution: artificial saliva composition

- $\mathrm{Na}_{3} \mathrm{PO}_{4}-3.9 \mathrm{mM}$

- $\mathrm{NaCl}_{2}-4.29 \mathrm{mM}$

- $\mathrm{KCl}-17.98 \mathrm{mM}$

- $\mathrm{CaCl}_{2}-1.10 \mathrm{mM}$

- $\mathrm{MgCl}_{2}-0.08 \mathrm{mM}$

- $\mathrm{H}_{2} \mathrm{SO}_{4}-0.50 \mathrm{mM}$

- $\mathrm{NaHCO}_{3}-3.27 \mathrm{mM}$

- Distilled water

Group I samples were treated with SDF once for 3 minutes. Group II and group III samples were treated with concerned remineralizing agent for 3 minutes application every 24 hours for 14 days. Postremineralization DIAGNOdent readings of samples were recorded with 72 hours, 7 days, and 14 days interval.

\section{Results}

The data were analysed by SPSS using one-way ANOVA and post hoc Bonferroni tests. The graph shows the mean values and differences in DIAGNOdent readings during each treatment. DIAGNOdent readings with one-way ANOVA is found to be statistically significant from baseline to postdemineralization $(p<0.001)$ and significant decrease in postremineralization $(p<0.001)$. After 72 hours of remineralization, DIAGNOdent values were approaching baseline values. Post hoc test was proved to be statistically significant at 7th and 14th day of remineralization with SDF showing maximum remineralization potential.

\section{Discussion}

Remineralization is a novel noninvasive management of early carious lesions, which bridges the traditional gap between preventive and invasive dentistry. ${ }^{8}$ The successful management using this technique requires detection of caries lesions at an early stage and correctly quantify the degree of mineral loss to ensure correct intervention. $^{9}$

In the past decade, several noninvasive methods for caries detection have been evaluated, ${ }^{10}$ that is, quantitative laser/lightinduced fluorescence ${ }^{11-15}$ electrical caries monitor, ${ }^{16-18}$ and digital imaging fiber-optic transillumination. ${ }^{19}$

KaVo DIAGNOdent (KAVO, Biberach, Germany) is a relatively new laser-based noninvasive instrument, which generates laser light with a wavelength of $655 \mathrm{~nm}^{20}$ to measure early demineralization. The laser light is absorbed by both organic and inorganic materials in the teeth and reemitted as fluorescence within the infrared region. In the presence of caries, fluorescence increases and the change is registered as an increased digital number. It is proposed that the enhanced fluorescence resulted from the integration of bacterial metabolites rather than crystalline disintegration. Various literature reports have shown the value of DIAGNOdent as a reliable noninvasive caries detecting device. ${ }^{21-23}$

In the present study, low-frequency (LF) values increased postdemineralization and subsequently decreased postremineralization. Similar results were demonstrated in studies conducted by Al-Khateeb et al., ${ }^{24}$ Eggertsson et al., ${ }^{25}$ Shi et al., ${ }^{23}$ Mendes et al., ${ }^{26}$ Pai et al., ${ }^{27}$ Bahrololoomi et al., ${ }^{28}$ and Patil et al. ${ }^{29}$ who also used DIAGNOdent to assess remineralization. The remineralization regimen followed in this study was comprised of 3-minute-daily application for 14 days. This is in accordance with the manufacturer's instructions. Pai et al. ${ }^{27}$ followed a similar regimen of 3-minute-daily application for 14 days.

Silver diamine fluoride is a topical fluoride solution that has been used for management of caries. Silver diamine fluoride is capable of efficiently halting the caries process, unlike other fluoride products that prevent the formation of new caries. ${ }^{30}$ Silver diamine fluoride has shown its clinical success on arresting the coronal caries of the primary teeth in children, ${ }^{31}$ permanent teeth in teenagers, ${ }^{32}$ and root caries of the elderly individuals. ${ }^{33}$ Silver diamine fluoride was also found to increase the mineral density of the artificial carious lesion, ${ }^{34}$ an ex vivo studies investigated the collected exfoliated primary teeth from the SDF clinical trials and found that a hardened and highly mineralized zone was formed in the outermost $150 \mu \mathrm{m}$ of an SDF-treated carious lesion. ${ }^{35,36}$

Silver is a well-known antibacterial agent and previous studies demonstrated that SDF inhibited cariogenic biofilm formation. ${ }^{34,37,38}$ Yamaga et al. suggested that the formation of 


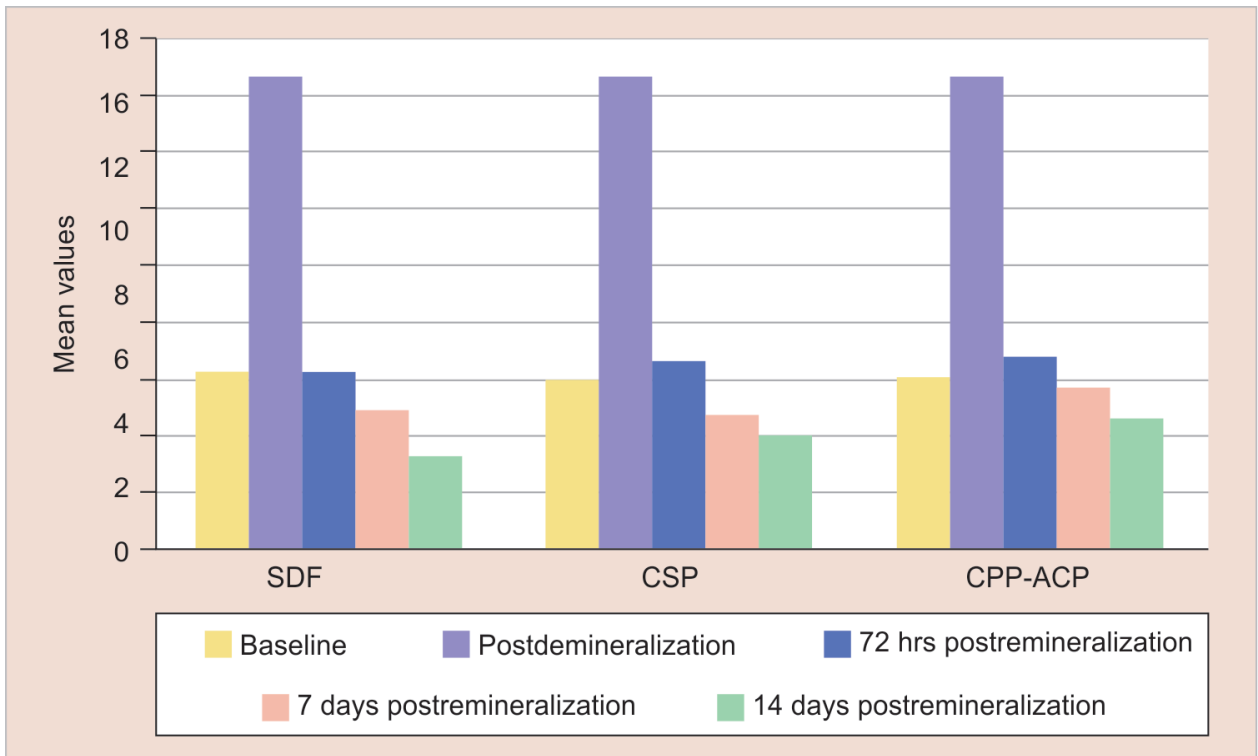

Fig. 1: The mean values and differences in DIAGNOdent readings during each treatment

calcium fluoride $\left(\mathrm{CaF}_{2}\right)$ and silver phosphate could be responsible for the prevention of dental caries and the hardening of a carious lesion. ${ }^{39}$ However, Suzuki et al. demonstrated the formation of $\mathrm{CaF}_{2}$ by mixing enamel powder with an SDF solution, but the amount of $\mathrm{CaF}_{2}$ dropped significantly when the materials were immersed into artificial saliva. They also found that silver phosphate disappeared after being immersed in artificial saliva and was replaced by silver chloride $(\mathrm{AgCl})$ and silver thiocyanate. ${ }^{40}$ In addition, Lou et al. found that a $\mathrm{CaF}_{2}$-like material and metallic silver were formed by mixing SDF with HA powder and gelatine (as a chemically representative protein), but the $\mathrm{CaF}_{2}$-like material dissolved and disappeared after washing with water. ${ }^{41}$ Therefore, the mode of SDF action is still unclear. An ex vivo study with SDF demonstrated a highly remineralized zone rich in calcium and phosphate in an arrested cavitated dentinal lesion of primary teeth with SDF application and suggested that clinical SDF application positively influences dentin remineralization. ${ }^{42}$ The present study also demonstrated that SDF is a potent remineralizing agent. The postremineralization values approached the baseline values after 72 hours of remineralization. Maximum remineralization was found during 7 th and 14 th days, which was statistically significant (Fig. 1 and Tables 1, 2).

Black staining of caries lesions after SDF application is a major disadvantage, which may cause dissatisfaction of the children and their parents. This staining may be eliminated by the application of potassium iodide (KI) after the SDF application. ${ }^{43}$ dos Santos et al. conducted a study using nano-silver fluoride and found it was effective to arrest dentine caries without causing dark staining. ${ }^{44}$

The concept of using CPP-ACP as a remineralizing agent was introduced in 1998, using casein for caries prevention was addressed in the 1980s, and ACP technology was introduced in the early 1990s. ${ }^{45}$ The technology containing milk protein CPP along with CPP-ACP also decreases tooth enamel demineralization and promotes enamel remineralization. It also inhibits plaque accumulation. Casein phospho peptide-amorphous calcium phosphate is highly soluble in water providing high concentrations of free calcium and phosphate ions several times higher than normally present in saliva causing remineralization. ${ }^{46}$
Table 1: ANOVA test

\begin{tabular}{llrll}
\hline & $d f$ & & $F$ & Sig. \\
\hline Baseline & Between groups & 2 & 0.248 & 0.782 \\
& Within groups & 27 & & \\
Demineralization & Between groups & 2 & 0.019 & 0.982 \\
& Within groups & 27 & & \\
Remineralization 72 hours & Between groups & 2 & 0.984 & 0.387 \\
& Within groups & 27 & & \\
Remineralization 7 days & Between groups & 2 & 5.771 & 0.008 \\
& Within groups & 27 & & \\
Remineralization 14 days & Between groups & 2 & 7.883 & 0.002 \\
& Within groups & 27 & & \\
\hline
\end{tabular}

Table 2: Post hoc tests: multiple comparisons-Bonferroni

\begin{tabular}{llll}
\hline Dependent variable & (I) group & (J) group & Sig. \\
\hline Remin_7 days & SDF & CSP & 1.000 \\
& & CPP-ACP & 0.048 \\
& CSP & SDF & 1.000 \\
& & CPP-ACP & 0.010 \\
Remin_14 days & CPP_ACP & SDF & 0.048 \\
& & CSP & 0.010 \\
& SDF & CSP & 0.126 \\
& & CPP-ACP & 0.001 \\
& CSP & SDF & 0.126 \\
& & CPP-ACP & 0.235 \\
& CPP_ACP & SDF & 0.001 \\
& & CSP & 0.235 \\
\hline
\end{tabular}

Other organic phosphates such as glycerophosphate, phytate, sodium dihydrogen phosphate salts, and calcium sucrose phosphate (CaSP)-calcium orthophosphate complex have been studied for their potential anticaries effect. Salivary calcium concentration is inversely related to solubility of enamel. Calcium 
is considered to be more efficient than phosphate in restricting the demineralization. A calcium phosphate ratio of 1:6 has been suggested for enamel remineralization. ${ }^{47}$ In the present study, CPP-ACP showed significant remineralization after 72 hours, but the difference LF values during remineralization period of 72 hours, 7 days, and 14 days were not significant (Fig. 1 and Tables 1, 2).

Calcium sucrose phosphate based on Anticay ${ }^{\oplus}$ technology is a mixture of CaSPs and inorganic calcium phosphates. It works by creation of an aqueous solution containing high concentration of calcium (10-12\%) and phosphate (8-10\%) by weight without precipitation. ${ }^{48}$ It is an effective remineralizing agent because of its solubility in water providing high concentrations of free calcium and phosphate ions several times higher than normally present in saliva. ${ }^{49}$ Calcium sucrose phosphate also inhibits the formation of plaque. ${ }^{50}$ Kaur et al. conducted an in vitro study comparing the effect of GC Tooth Mousse and toothmin toothcream on microhardness of bleached enamel surface and found that remineralization was numerically better in toothmin group, which showed increased microhardness. ${ }^{51}$ An in vitro study by Raghu et al. evaluated the remineralization potential of CSP on demineralized enamel and found that toothmin increased microhardness of enamel and enhanced surface smoothness with significant remineralizing potential. ${ }^{7}$ Casein sucrose phosphate group showed a significant difference in postdemineralization and postremineralization values in this study also with maximum remineralization during 7 th and 14th day (Fig. 1 and Tables 1, 2).

To summarize, as found in previous studies, the results of present study has also demonstrated that the chosen test agents can induce remineralization of early enamel lesions, thus avoiding the need for an invasive treatment at a later time. This study reemphasizes the importance of the proverb "Prevention is better than cure."

\section{Clinical Significance}

To the best of our knowledge, this is the first study to compare the remineralizing potential of these 3 agents simultaneously using laser fluorescence.

\section{Conclusion}

The following conclusion were made from the findings obtained from the present study:

- All test agents have highly significant remineralizing potential.

- Among 3 agents compared, SDF showed maximum remineralizing efficacy followed by CSP and CPP-ACP respectively.

- Thus, clinical application of these agents will be a novel noninvasive patient-friendly and effective method to treat reversible carious lesions.

However, further in vivo studies are required to reassure the superiority of SDF over CSP and CPP-ACP.

\section{References}

1. Kamath $\mathrm{P}$, Nayak R, Kamath $\mathrm{SU}$, et al. A comparative evaluation of the remineralization potential of three commercially available remineralizing agents on white spot lesions in primary teeth: An in vitro study. J Indian Soc Pedod Prev Dent 2017;35(3):229-237. DOI: 10.4103/JISPPD.JISPPD_242_16.
2. Hara A, Zero D. The caries environment: Saliva, pellicle, diet, and hard tissue ultrastructure. Dent Clin North Am 2010;54(3):455-467. DOI: 10.1016/j.cden.2010.03.008.

3. Kwang $S$, Abbott $P$. The presence and distribution of bacteria in dentinal tubules of root filled teeth. Int Endod J 2014;47(6):600-610. DOI: 10.1111/iej.12195.

4. Scaramucci T, Carvalho JC, Hara AT, et al. Causes of Dental Erosion: Intrinsic Factors. Berlin: Springer International Publishing; 2015; pp. 35-67.

5. Featherstone JD, Lussi A. Understanding the chemistry of dental erosion. Monogr Oral Sci 2006;20:66-76.

6. Higham S, [webpage on the Internet]. Caries Process and Prevention Strategies: Demineralization/Remineralization. Available from: http:// www.dentalcare.com/media/en-US/education/ce372/ce372.pdf. Accessed June 23, 2016.

7. Raghu TN, Ananthakrishna S. Remineralization potential of calcium sucrose phosphate on demineralized enamel: results of an in vitro study. Journal of International Oral Health 2016;8(6):704.

8. Pradeep K, Rao PK. Remineralizing agents in the non-invasive treatment of early carious lesions. Int J Dent Case Rep 2011;1: 73-84.

9. Pretty IA. Caries detection and diagnosis: novel technologies. J Dent 2006;34(10):727-739. DOI: 10.1016/j.jdent.2006.06.001.

10. Angmar-Månsson $B$, ten Bosch JJ. Advances in methods for diagnosing coronal caries. A review. Adv Dent Res 1993;7(2):70-79. DOI: $10.1177 / 08959374930070021801$.

11. de Josselin de Jong $E$, Sundström F, Westerling $\mathrm{H}$, et al. A new method for in vivo quantification of changes in initial enamel caries with laser fluorescence. Caries Res 1995;29(1):2-7. DOI: 10.1159/000262032.

12. Angmar-Månsson B, Al-Khateeb S, Tranæus S. Monitoring the caries process: Optical methods for clinical diagnosis and quantification of enamel caries. Eur J Oral Sci 1996;104(4 Pt 2):480-485. DOI: 10.1111/j.1600-0722.1996.tb00116.x.

13. Al-Khateeb S, ten Cate JM, Angmar-Månsson B, et al. Quantification of formation and remineralization of artificial enamel lesions with a new portable fluorescence device. Adv Dent Res 1997;11(4):502-506. DOI: 10.1177/08959374970110041801.

14. Al-Khateeb S, Oliveby A, de Josselin de Jong E, et al. Laser fluorescence quantification of remineralization in situ of incipient enamel lesions: Influence of fluoride supplements. Caries Res 1997;31(2):132-140. DOI: 10.1159/000262388.

15. Ferreira Zandoná $A G$, Analoui $M$, Beiswanger $B B$, et al. An in vitro comparison between laser fluorescence and visual examination for detection of demineralization in occlusal pits and fissures. Caries Res 1998;32(3):210-218. DOI: 10.1159/000016455.

16. le $\mathrm{YL}$, Verdonschot $\mathrm{EH}$, Schaeken $\mathrm{MJ}$, et al. Electrical conductance of fissure enamel in recently erupted molar teeth as related to caries status. Caries Res 1995;29(2):94-99. DOI: 10.1159/000262048.

17. Huysmans $M C$, Longbottom $C$, Hintze $H$, et al. Surface-specific electrical occlusal caries diagnosis: reproducibility, correlation with histological lesion depth, and tooth type dependence. Caries Res 1998;32(5):330-336. DOI: 10.1159/000016468.

18. MC Huysmans, Longbottom C, Pitts NB. Electrical methods in occlusal caries diagnosis: An in vitro comparison with visual inspection and bite-wing radiography. Caries Res 1998;33:324-329.

19. Schneiderman A, Elbaum M, Shultz T, et al. Assessment of dental caries with digital imaging fiber-optic transillumination (DIFOTI): In vitro study. Caries Res 1997;31(2):103-110. DOI: 10.1159/ 000262384.

20. Hibst R, Gall R. Development of a diode laser-based fluorescence caries detector. Caries Res 1998;32:294.

21. Pinelli C, Campos Serra M, de Castro Monteiro Loffredo L. Validity and reproducibility of a laser fluorescence system for detecting the activity of white-spot lesions on free smooth surfaces in vivo. Caries Res 2002;36(1):19-24. DOI: 10.1159/000057585.

22. Buck T, Pellegrini P, Sauerwein R, et al. Elastomeric-ligated vs selfligating appliances: A pilot study examining microbial colonization 
and white spot lesion formation after 1 year of orthodontic treatment. Orthodontics (Chic) 2011;12(2):108-121.

23. Shi XQ, Tranaeus $S$, Angmar-Mansson B. Comparison of QLF and DIAGNOdent for quantification of smooth surface caries. Caries Res 2001;35(1):21-26. DOI: 10.1159/000047426.

24. Al-Khateeb S, Forsberg CM, de Josselin de Jong E, et al. A longitudinal laser fluorescence study of white spot lesions in orthodontic patients. Am J Orthod Dentofacial Orthop 1998;113(6):595-602. DOI: 10.1016/ S0889-5406(98)70218-5.

25. Eggertsson $\mathrm{H}$, Analoui $\mathrm{M}$, van der Veen $\mathrm{M}$, et al. Detection of early interproximal caries in vitro using laser fluorescence, dye-enhanced laser fluorescence and direct visual examination. Caries Res 1999;33(3):227-233. DOI: 10.1159/000016521.

26. Mendes FM, Pinheiro SL, Bengtson AL. Effect of alteration in organic material of the occlusal caries on diagnodent readings. Braz Oral Res 2004;18(2):141-144. DOI: 10.1590/S1806-83242004000200009.

27. Pai D, Bhat SS, Taranath A, et al. Use of laser fluorescence and scanning electron microscope to evaluate remineralization of incipient enamel lesions remineralized by topical application of casein phospho peptide amorphous calcium phosphate (CPP-ACP) containing cream. J Clin Pediatr Dent 2008;32(3):201-206. DOI: 10.17796/jcpd.32.3.d08 $3470201 \mathrm{~h} 58 \mathrm{~m} 13$.

28. Bahrololoomi Z, Musavi SA, Kabudan M. In vitro evaluation of the efficacy of laser fluorescence (DIAGNOdent) to detect demineralization and remineralization of smooth enamel lesions. J Conserv Dent 2013;16(4):362-366. DOI: 10.4103/0972-0707. 114360.

29. Patil N, Choudhari S, Kulkarni S, et al. Comparative evaluation of remineralizing potential of three agents on artificially demineralized human enamel: An in vitro study. J Conserv Dent 2013;16(2):116-120. DOI: 10.4103/0972-0707.108185.

30. Gao SS, Zhao IS, Niraishi N, et al. Clinical trials of silver diamine fluoride in arresting caries among children a systematic review. JDR Clin Trans Res 2016;1(3):201-210. DOI: 10.1177/2380084416661474.

31. Chu CH, Lo EC, Lin HC. Effectiveness of silver diamine fluoride and sodium fluoride varnish in arresting dentin caries in Chinese pre-school children. J Dent Res 2002;81(11):767-770. DOI: 10.1177/ 0810767.

32. Chu $\mathrm{CH}$, Lee $\mathrm{AH}$, Zheng $\mathrm{L}$, et al. Arresting rampant dental caries with silver diamine fluoride in a young teenager suffering from chronic oral graft vs host disease post-bone marrow transplantation: A case report. BMC Res Notes 2014;7:3. DOI: 10.1186/1756-0500-7-3.

33. Tan HP, Lo EC, Dyson JE, et al. A randomized trial on root caries prevention in elders. J Dent Res 2010;89(10):1086-1090. DOI: 10.1177/0022034510375825.

34. Mei ML, Li QL, Chu CH, et al. Antibacterial effects of silver diamine fluoride on multi-species cariogenic biofilm on caries. Ann Clin Microbiol Antimicrob 2013;12:4. DOI: 10.1186/1476-0711-12-4.

35. Chu CH, Lo EC. Microhardness of dentine in primary teeth after topical fluoride applications. J Dent 2008;36(6):387-391. DOI: 10.1016/j. jdent.2008.02.013.
36. Mei ML, Ito L, Cao $Y$, et al. The inhibitory effects of silver diamine fluorides on cysteine cathepsins. J Dent 2014;42(3):329-335. DOI: 10.1016/j.jdent.2013.11.018.

37. Chu CH, Mei L, Seneviratne CJ, et al. Effects of silver diamine fluoride on dentine carious lesions induced by streptococcus mutans and Actinomyces naes/undii biofilms. Int J Paediatr Dent 2012;22(1):2-10. DOI: 10.1111/j.1365-263X.2011.01149.x.

38. Mei ML, Chu CH, Low KH, et al. Caries arresting effect of silver diamine fluoride on dentine carious lesion with S. Mutans and L. Acidophilus dual-species cariogenic biofilm. Med Oral Patol Oral Cir Bucal 2013;18(6):e824-e831. DOI: 10.4317/medoral.18831.

39. Yamaga R, Nishino $M$, Yoshida $S$, et al. Diammine silver fluoride and its clinical application. J Osaka Univ Dent Sch 1972;12:1-20.

40. Suzuki T, Nishida M, Sobue S, et al. Effects of diammine silver fluoride on tooth enamel. J Osaka Univ Dent Sch 1974;14:61-72.

41. Lou YL, Botelho MG, Darvell BW. Reaction of silver diamine [corrected] fluoride with hydroxyapatite and protein. J Dent 2011;39(9):612-618. DOI: 10.1016/j.jdent.2011.06.008.

42. Mei ML, Ito L, Cao Y, et al. An ex vivo study of arrested primary teeth caries with silver diamine fluoride therapy. J Dent 2014;42(4):395-402. DOI: 10.1016/j.jdent.2013.12.007.

43. Knight GM, Mclntyre JM, Craig GG, et al. An in vitro model to measure the effect of a silver fluoride and potassium iodide treatment on the permeability of demineralized dentine to streptococcus mutans. Aust Dent J 2005;50(4):242-255. DOI: 10.1111/j.1834-7819.2005.tb00367.x.

44. dos Santos Jr VE, Vasconcelos Filho A, Targino AG, et al. A new "Silver-Bullet" to treat caries in children-nano silver fluoride: a randomised clinical trial. J Dent 2014;42(8):945-951. DOI: 10.1016/ j.jdent.2014.05.017.

45. Jain $P$, Kaul $R$, Saha $S$, et al. Smart materials-making pediatric dentistry bio-smart. Int J Pedod Rehabil 2017;2(2):55. DOI: 10.4103/ijpr.ijpr_8_17.

46. Lata S, Varghese NO, Varughese JM. Remineralization potential of fluoride and amorphous calcium phosphate-casein phospho peptide on enamel lesions: An in vitro comparative evaluation. J Conserv Dent 2010;13(1):42-46. DOI: 10.4103/0972-0707.62634.

47. Exterkate RA, Damen JJ, ten Cate JM. A single-section model for enamel de- and remineralization studies 1 . The effects of different ca/P ratios in remineralization solutions. J Dent Res 1993;72(12): 1599-1603. DOI: 10.1177/00220345930720121201.

48. Available from: http://www.biodentalremin.com/. [Last accessed on 2015 Dec 28].

49. Jamadar $A B$, Uppin VM, Pujar M, et al. Comparative evaluation of different remineralizing agents on the microhardness of bleached enamel surface an in vitro study. Paripex-Indian Journal of Research 2018;6(12)

50. Reema SD, Lahiri PK, Roy SS. Review of casein phosphopeptidesamorphous calcium phosphate. Chin J Dent Res 2014;17:7-14.

51. Kaur G, Sanap AU, Agarwal SD, et al. Comparative evaluation of two different remineralizing agents on the microhardness of bleached enamel surface: results of an in vitro study. Indian J Dent Res 2015;26(2):176. DOI: 10.4103/0970-9290.159154. 